\title{
Economic assessment for additive manufacturing of automotive end-use parts through digital light processing (DLP)
}

\author{
Mathias Wiese $^{\mathrm{a}, \mathrm{b}, *}$, Alexander Kwauka ${ }^{\mathrm{a}}$, Sebastian Thiede ${ }^{\mathrm{b}, \mathrm{c}}$, Christoph Herrmann $^{\mathrm{b}, \mathrm{d}}$ \\ a Polymer Additive Manufacturing Center, AUDI AG, Auto-Union-Straße 1, Ingolstadt 85045, Germany \\ ${ }^{\mathrm{b}}$ Chair of Sustainable Manufacturing and Life Cycle Engineering, Institute of Machine Tools and Production Technology, Technische Universität Braunschweig, \\ Langer Kamp 19b, Braunschweig 38106, Germany \\ c Chair of Manufacturing Systems, Department of Design, Production and Management, Faculty of Engineering Technology, University of Twente, \\ Drienerlolaan 5, Enschede 7522NB, The Netherlands \\ d Fraunhofer Institute for Surface Engineering and Thin Films (IST), Bienroder Weg 54e, Braunschweig 38108, Germany
}

\section{A R T I C L E I N F O}

\section{Article history:}

Available online xxx

\section{Keywords:}

Rapid manufacturing

Additive manufacturing

Cost estimation

Digital light processing (DLP)

Sensitivity analysis

Automotive engineering

\begin{abstract}
A B S T R A C T
Within the last years, digital light processing (DLP) became a viable solution for the manufacturing of end-use parts in various industries among other additive manufacturing (AM) processes. As the number of applications realized in a rapid manufacturing (RM) approach grows, it is necessary to understand the process economics better when moving from laboratory and prototyping applications into the costsensitive production scale. This paper presents a production-centered economic assessment of DLP production in the early product development process, based on Continuous Liquid Interphase Printing (CLIP). It is applied to an automotive exterior part case study to reveal expected process economics and estimate part prime cost for different printer sizes and automation concepts. A subsequent sensitivity analysis assesses the influence of relevant cost drivers and identifies opportunities for further cost savings when producing end-use parts with DLP. Results may help machine OEMs and application developers in cost optimization and decision making in RM.
\end{abstract}

(C) 2021 CIRP

\section{Introduction}

The manufacturing sector for polymeric automotive parts and components is dominated by well-explored and widely used manufacturing technologies such as injection molding, insert molding and back molding [1]. However, additive manufacturing (AM) is considered as an emerging and conceivably disrupting technology for polymer processing [2,3]. Its relevance for the production of end-use parts is expected to increase within the next years [4]. Due to significant improvements, AM materials and processes are now found to be partially fulfilling automotive part requirements [5]. As a consequence, AM is not only used for rapid prototyping but also applied for rapid manufacturing (RM) [6] and cost of end-use parts manufactured with AM become an important factor to identify positive business cases for this manufacturing technology. Addressing these trends, this paper presents an approach for cost assessment of end-use parts printed with digital light processing (DLP). The approach is centered around the

\footnotetext{
* Corresponding author at: Polymer Additive Manufacturing Center, AUDI AG, Auto-Union-Straße 1, Ingolstadt 85045, Germany.

E-mail address: mathias.wiese@audi.de (M. Wiese).
}

Continuous Liquid Interphase Process (CLIP) technology which can be assigned to the DLP process family.

Introduction to DLP: the example of CLIP

In general, DLP systems are based on a vat photopolymerization process, working with a light mask projector [7]. This principle is derived from the method of dynamic mask projection, which was originally enabled by a digital micro-mirror device from Texas Instruments [8]. These technologies build a part in a layer-wise approach by selective curing of a liquid photosensitive resin when exposed to an UV-light mask [8,9]. CLIP recently emerged among these technologies and delivered high production speed paired with multiple programmable resins to form end-use parts [10]. Its working principle is illustrated in Fig. 1.

At the beginning of a print, the build platform or carrier is submerged in the resin reservoir. An oxygen-permeable and optically transparent window creates a dead zone, a thin layer of oxygen, between its surface and the photopolymer resin. From beneath, a digital light processor irradiates a defined cross-section layer of the three-dimensional object into the liquid and solidifies the exposed sections of photopolymer resin. During the build process the build platform continuously moves upwards while 


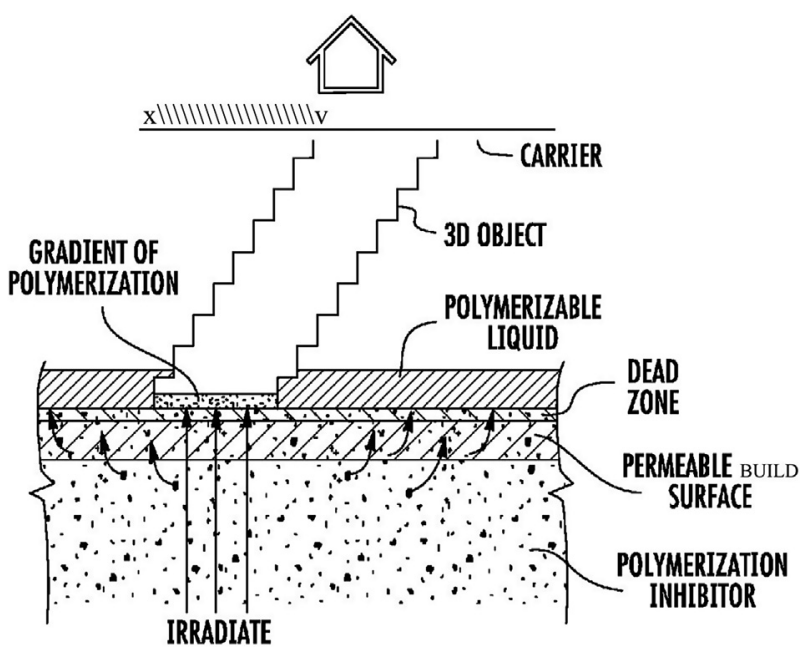

Fig. 1. Illustration of the working principle of the CLIP technology [11].

maintaining a thin gradient of polymerization between the previously cured layer and the dead zone. The oxygen layer prevents the cured resin from sticking to the reservoir. Through this continuous process, a three-dimensional object is formed. Upon print finish, the part and its support structures can be removed from the build platform. After removal of excess resin, the part is additionally cured in a heating chamber to enhance the mechanical and thermal properties [11].

Current trends and industry needs for end-use part production with $D L P$

The CLIP technology recently realized multiple end-use part applications in the automotive, sports equipment and apparel industries using rigid epoxy-based and soft elastic polyurethanebased materials. Table 1 presents some of these published applications.

As presented, most applications are driven by customization purposes, often in combination with a specific design for additive manufacturing (DfAM). In the automotive sector, cost-effective small series production is also an important driving force [12-14]. Applications in sports and apparel are influenced by the customer's desires or increase the functional value of the application through geometries that are tailored to the customer's body dimensions. For example, this process enhances the impact absorption of football helmet cushions, comfort of bicycle saddles or performance of running shoes [15-17]. These recent developments of end-use products in the DLP domain triggered market entry of new printer manufacturers with open-material systems $[19,20]$ in collaboration with material suppliers to increase the spectrum of materials for DLP and enable new applications [21-23]. As the systems aim to leave the domain of rapid prototyping, manufacturers present solutions to automatize the processes further. These solutions include automated loading and unloading of DLP machines by robots [24] or integrating multiple post-processing steps in a single unit [19].

With respect to all these emerging trends and growing possibilities, potential end-users need more profound understanding of cost-efficiency in series production with DLP. In general, the economics of AM influence the applicability of the technology for end-use part manufacturing as cost sensitivity of the user significantly increases when moving from rapid prototyping to rapid manufacturing. As a consequence, users need versatile cost evaluation tools which support them with detailed and specific information in the early product development process by providing:

- Detailed cost breakdowns

- Assessment of production system alternatives (e.g., different printer sizes)

- Evaluation of influence of operation concepts (e.g., partial automation)

- Sensitivity analysis regarding important cost drivers

- Extensibility and integrability in further product development (e.g., production line simulation)

Generated insights equip engineers and decision makers with important information regarding whether DLP in general can be considered a competitive manufacturing approach. Taken together, also further decision making regarding, e.g., a favorable location of production or following a make or buy approach is possible.

By reviewing and adapting existing cost modeling approaches for AM, this paper develops a cost assessment framework for DLP, which targets economic technology evaluation in the early product development process. It addresses the mentioned areas of decision support and is subsequently applied to a case study for early economic evaluation of DLP production of an automotive series part.

The applicability of existing cost modeling techniques and first approaches to quantify economics of AM processes, especially with regard to DLP, are addressed in the following section.

\section{Cost modeling techniques and derivation of research need}

\section{Available cost modeling techniques}

Today, a broad spectrum of available cost modeling techniques exists. These comprise analogical techniques, parametric techniques and analytical techniques [25-27]. To address the respective techniques' major advantages, drawbacks as well as their scope of application in the context of (AM) product development, they are assessed one by one in the following paragraphs.

Table 1

Overview of recently published end-use part applications of the CLIP technology.

\begin{tabular}{|c|c|c|c|c|}
\hline Industry & Application & Material class & Driver & Ref. \\
\hline \multirow[t]{4}{*}{ Automotive } & Personalized side scuttles & EPX & Customization & [12] \\
\hline & Brake bracket & EPX & Small series & [13] \\
\hline & Air duct split & EPX & Small series & [14] \\
\hline & Fuel tank cap & EPX & Small series & [14] \\
\hline \multirow[t]{4}{*}{ Apparel \&Sports } & Running shoe midsoles & EPU & DfAM & [15] \\
\hline & Bicycle saddle padding & EPU & DfAM & [16] \\
\hline & Football helmet cushion & EPU & DfAM & [17] \\
\hline & Eyewear frame cushions & EPU & DfAM & [18] \\
\hline
\end{tabular}




\section{Analogical techniques}

Analogical methods are using a certain codification for parts, frequently a morpho-dimensional codification, which relates to a typical solution for each codification (e.g., a manufacturing process, typical cost range) [28]. They are characterized by adjusting the cost of a similar product relative to differences between it and the target product [25]. This approach is one of the most successful approaches in the early design stage [29], where it profits from advantages like its fast application, clear relation of causes and effects and possible accuracy [27]. However, it requires expert knowledge for the definition of adjustment factors, identification of appropriate analog parts and build-up of the substantial and detailed database [27]. As a consequence, first implementation of this technique usually implies a high investment, which poses a high barrier especially for smaller-sized enterprises [28].

\section{Parametric techniques}

By bringing parameters of a part into a mathematical correlation with expected costs via statistical analysis, parametric cost estimation techniques enable cost prediction within part families [27]. Consequently, these methods are only feasible when two conditions are met: First, the product must be a member of a closely related product family. Secondly, this family must have many members with already established cost for provision of historical data [29]. Given this data exists, parametric techniques are suited for cost estimation in the early design stage [27]. However, while they are fairly easy to perform and do not require expert knowledge for their application, they often function like a 'black box', making it difficult for the user to understand elements of the manufacture, identify cause-and-effect relationships or justify the results. Moreover, if the context of production is altered, the estimation must be repeated and results need to be justified again $[27,28]$.

\section{Analytical techniques}

In analytical cost estimation techniques, all work steps with their costs for material, work, infrastructure, etc. are added up to the product's cost in a bottom-up approach. This procedure requires deep understanding of the process, its interactions and part design details [27]. Degree of detail and a clear cause-andeffect relationship are major advantages of this technique [25]. Furthermore, it is able to provide insight into cost contributors and cost drivers. Also, miscalculation of single elements does not necessarily compromise the entire estimation [27]. While it is practically adaptable to changing workshop contexts [28], a new estimate must be built up for each alternative scenario, resulting in significant effort. [27]. Due to this data-intense approach, it is rather suited for later stages of the product development process. However, when no historic data is available (e.g., for new technologies or products), this technique is the only cost modeling approach applicable [27].

\section{Use in the product development process}

As already partially addressed, the different cost estimation techniques demand varying degrees of available data and formalization of the product and manufacturing process. Thus, their individual position and contribution in the product development process differs as illustrated in Fig. 2.

Resulting from the statements in "Introduction" section, the targeted area for support through the proposed cost modeling approach is highlighted. It spans from the late product definition phase to the beginning of the production phase with main emphasis on the early (pre-)development phase. Here, first data concerning the product's geometry, requirements and qualified processes is available, enabling process-specific analytical cost

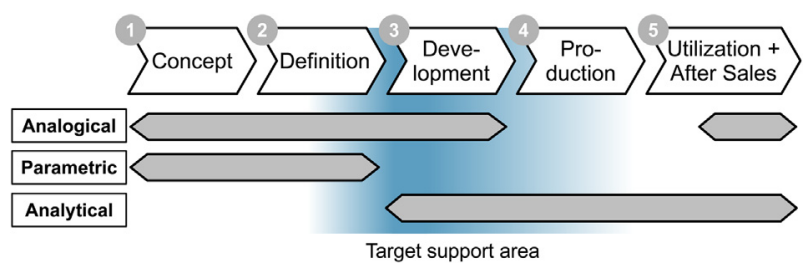

Fig. 2. Use of cost estimation techniques in the product development process and target support area for this concept [adapted from [28]].

evaluation through, e.g., an activity-based costing approach $[27,30]$. With regard to all available cost modeling alternatives, two main aspects need to be considered: First, with a low presence of $\mathrm{AM}$ in end-use part manufacturing, techniques relying on historic data like analogical or parametric modeling are less favorable due to low data availability. Secondly, analytical cost modeling not only represents the only technically feasible method in these circumstances, but also offers support and opportunities for extension (e.g., through integration into production-oriented discrete event simulation [31]) in the following steps of product development. In a more detailed investigation, existing analytical cost models for AM end-use parts produced in a rapid manufacturing approach are discussed in the next section.

\section{Analytic cost modeling in context of rapid manufacturing}

Several researchers dealt with AM cost identification in the past, as showed by Costabile et al. [32]. Thus, the literature review focuses on the key elements of the following analysis. This comprises the use of AM in a rapid manufacturing context, coverage of DLP processes, production with single geometries, varying printer size and cost driver analysis. In terms of rapid manufacturing, Hopkinson and Dickens tested production volume of parts including a cost model to compare part cost of different AM technologies like selective laser sintering (SLS), fused deposition modeling (FDM) and stereolithography (SLA) with injection molding. Their model determines the break-even point between the technologies and injection molding [33]. Ruffo et al. improved this model by integrating further cost factors like administrative and overhead cost for identification of scaling effects [34]. Based on the work of Ruffo, Charalambis et al. developed a first cost model for DLP using a specifically designed precision printer without regard to rapid manufacturing. Although this generic cost model is not restricted to DLP technologies, specific assumptions of parameters and limitations are derived from photopolymerization processes and thus need adjustment when applied to other AM technologies. The developed model sums up the cost for preprocessing efforts, material, build process, post-processing activities and overhead allocations [35]. Cunningham et al. and Schröder et al. extended cost analysis regarding cost driver influence. They conducted a sensitivity analysis (SA) on stereolithography (SLA), selective laser sintering (SLS), fused deposition modeling (FDM), selective laser melting (SLM), electron beam melting (EBM) and wire and arc additive manufacturing (WAAM) to uncover special economic effects or rank the cost drivers by their impact on the underlying cost models [36,37]. Yang and Li introduced a cost model with consecutive sensitivity analysis for production with mixed geometries using mask image projection stereolithography, which shares certain process similarities with DLP [38]. A brief overview of the different models' coverage of single geometry production (SGP), DLP and SA is presented in Table 2.

All approaches have in common, that they are based on a bottom-up analytical cost modeling approach, underlining the findings in "Use in the product development process" section. 
Table 2

Overview of model coverage in identified cost modeling approaches.

\begin{tabular}{llll}
\hline Reference & SGP & SA & DLP \\
\hline Hopkinson and Dickens [33] & $\bullet$ & & \\
Ruffo et al. [34] & $\bullet$ & & $\bullet$ \\
Charalambis et al. [35] & $\bullet$ & $\bullet$ & \\
Schröder et al. [36] & $\bullet$ & $\bullet$ & $\bullet$ \\
Cunningham et al. [37] & $\bullet$ & $\bullet$ & \\
Yang and Li [38] & & & \\
\hline
\end{tabular}

\section{Research need}

With regard to the findings in "Introduction" and "Cost modeling techniques and derivation of research need" sections, the need for a DLP cost assessment framework can be identified, which covers a rapid manufacturing context with a single geometry production approach and support of sensitivity analysis for cost driver evaluation. From a practical standpoint, producing end-use parts with DLP implies efficient and optimized build processes. It is questionable if a mixed geometry approach will be adopted for series manufacturing. Furthermore, the use of larger, more productive DLP systems is usually preferred over the use of small systems. Thus, the effect of printer platform size within the DLP technology family needs to be considered when selecting the right platform for series production. Especially in series manufacturing, users need to identify opportunities for further cost savings and back decisions, e.g., regarding whether to make or buy. Ideally, the assessment approach supports in the early development phases and provides an opportunity for further extension towards the production phase. This comprises, for example, a possible integration into dynamic simulation of production systems, which can be done when first production layouts are existent and availability and precision of data is very high.

Addressing these needs in research and industrial practice, the following introduces an assessment framework based on a static cost model for prime cost estimation in a DLP end-use part manufacturing environment during the early product development phase. Its activity-based approach aims to provide detailed cost insights (e.g., through application of cost driver sensitivity analysis) and offers the possibility for further extension or integration. Subsequent application to an automotive exterior part case study reveals differences in part cost on different platform sizes, potentials for cost savings through automation and influence of selected cost drivers in a subsequent sensitivity analysis.

\section{Methodology}

\section{Overview of method and implementation}

For better understanding, the fundamental framework for cost assessment is shown in Fig. 3, providing an overview about its elements, tools and deployment.

On the input level (1), build geometry data and machine parameters need to be gathered using the machine interfaces and/ or a nesting software like Materialise MAGICS. Depending on the amount of already available data and the needed accuracy, the time span for this step varies. For example, if print experiments are required to collect data, which cannot be directly derived from historic evaluations or digital print job planning, it extends from minutes to several hours. The evaluation level (2) comprises the activity-based cost model and sensitivity analysis module, which are implemented in python scripts. This enables processing of large

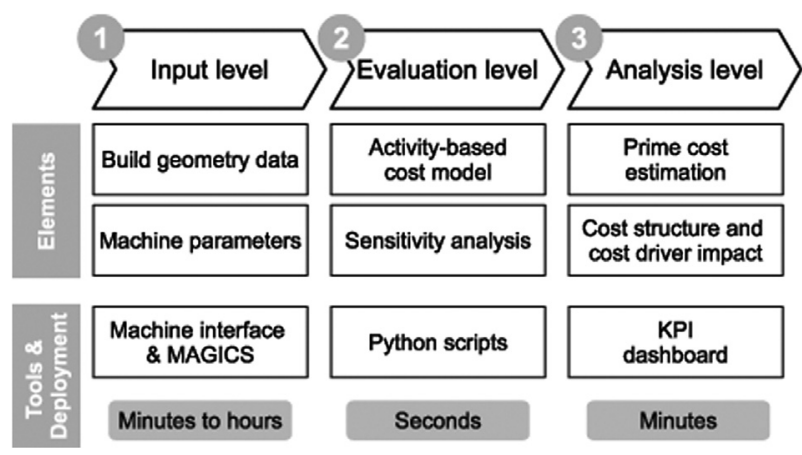

Fig. 3. Underlying methodological framework for cost assessment.

data amounts, e.g., coming from multiple parallel evaluations, and ensures repeatability of the evaluation in a very short time span. In this step, the scripts carry out the evaluation and cost modeling according to the parameters specified by geometry, print experiments and estimations. The analysis level (3) gives insight into the estimated prime cost for the respective part's production, the underlying cost structure and cost driver impact. For fast and comprehensive visual analysis of the key performance indicators (KPIs), the analysis can be coupled to a python-based KPI dashboard. Based on the results, different system configurations, cost driver impacts and potentials for further improvement of cost performance can be evaluated. The central elements defining the cost model and sensitivity analysis are described in the following, before the framework is applied to a case study in "Application to a case study" section.

\section{Reference process chain and system boundary}

The reference process chain for the assessment is depicted in Fig. 4. With three major steps, pre-processing, processing and postprocessing, the system boundary covers all directly print-related activities to manufacture a blank part. Following finishing steps (e.g., subsequent surface treatments like painting) are not covered.

Pre-processing encompasses the activity sequence of nesting, data transfer to the machines, resin dispense and loading of the printer platform into the machines. The latter two manual activities can be automated through robot handling. During processing, the print is executed and subsequent unloading of the build platform is either done manually or automatically. Postprocessing involves washing of the green parts, removal of support structures, cleaning of the build platform for subsequent jobs and thermal curing of the green parts.

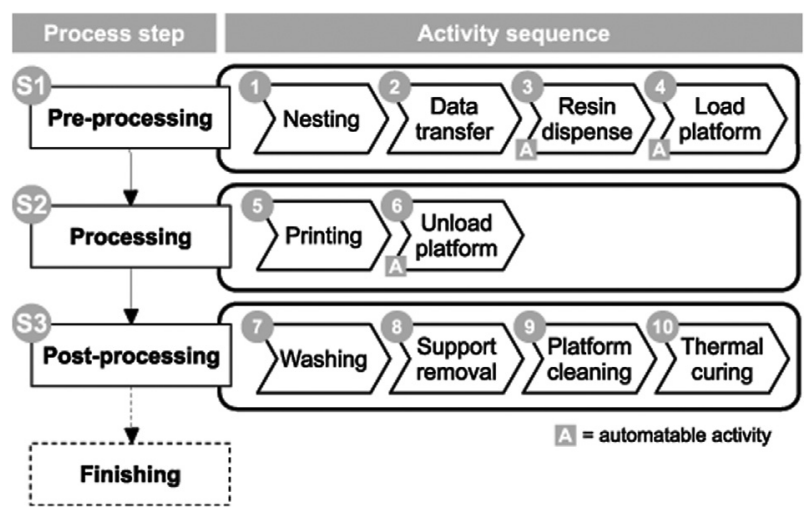

Fig. 4. Process steps and activity sequence for the considered process chain. 


\section{Cost structure}

For the definition of the cost model, the underlying cost structure and way of cost calculation is assessed. To determine the prime cost per part, a calculation based on machine hour rates and differentiated overheads is applied. In general, the prime cost can be broken down into production cost and sales and administration (S\&A) overheads, as illustrated in Fig. 5. Production cost are determined by material cost, summarizing the cost of production materials and their overheads, and manufacturing cost, comprising labor cost and manufacturing overheads.

A detailed view on the manufacturing cost in Fig. 5 is provided in Fig. 6. In manufacturing overheads, the depreciation and lease cost, calculatory interests, room and energy cost as well as maintenance cost constitute the machine cost. Together with labor cost and remaining overheads, machine cost are a central cost component of manufacturing cost.

This cost structure builds the base for the definition of the cost model in "Cost model" section.

\section{Cost model}

Using elements of the models presented in "Cost modeling techniques and derivation of research need" section and the cost structure introduced in "Cost structure" section as a baseline, the cost model defines cost-estimating relationships (CERs) for the parameters. For a complete overview of all involved parameters, calculations and resulting CERs, comprehensive tables are provided at the end of this article in Appendix A. Following the idea of production at an ideal AM part supplier facility, the part production is assumed to run $24 \mathrm{~h}$ in three shifts. This implies that apart from printers, also the shared pre- and post-processing equipment like washers, resin dispensers and ovens for post-processing is highly utilized and job distribution is done accordingly. The cost model is designed to analyze effects of partially automated production. Concepts involve a robot for loading and unloading operations of printers and part washer as well as automated resin dispensing during pre-processing. These automated tasks can be triggered to manual execution to evaluate potential cost savings through automation.

As illustrated in Fig. 7, prime cost are composed of four major cost blocks. These blocks contain CERs for labor cost, material cost, machine cost and overhead respectively S\&A cost. The color coding of these components is also found in the subsequent cost analysis charts in Fig. 9 in "Calculated prime cost per part" section.

Manufacturing cost result from machine hour and labor rates in combination with the respective process and machine times. Material cost depends on resin cost, the geometrical properties of the part, its support and excess material which is not solidified during a print. Together, material cost, machine cost and labor cost form the manufacturing cost. Applying standard overhead rates for

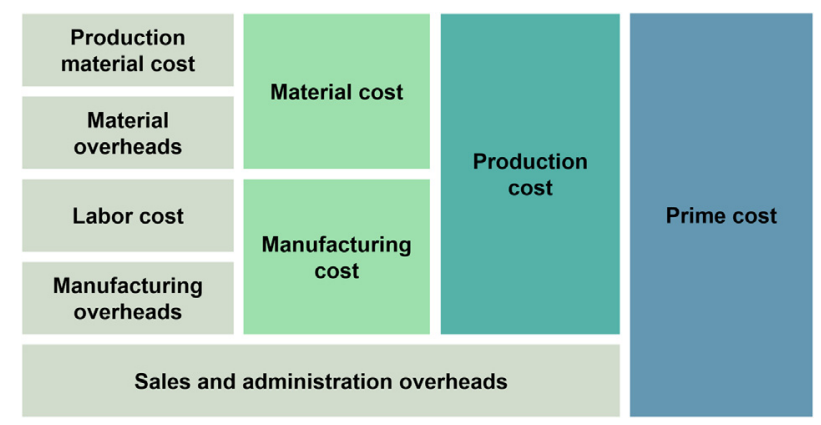

Fig. 5. Components of prime cost [adapted from Horsch [39]].

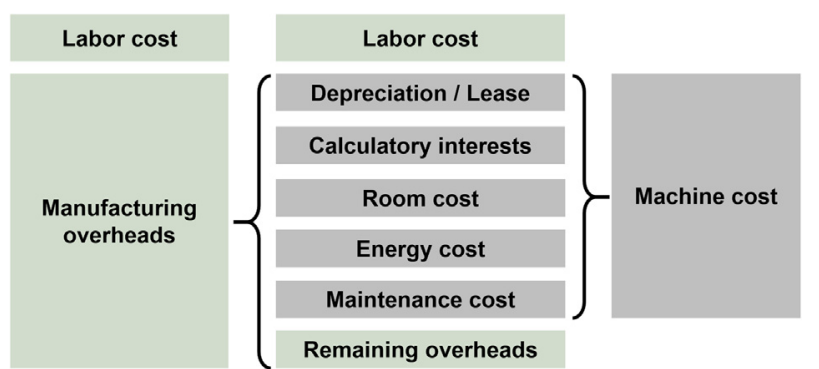

Fig. 6. Machine cost as a component of manufacturing cost [adapted from Plinke [40]].

polymer processing facilities as overhead and S\&A cost, prime cost per part can be calculated assuming a yield factor. As a profit margin is not applied, the prime cost cannot be treated as an estimated net offer price.

In favor of readability, the next paragraphs only introduce central CERs of the model. A detailed summary of all involved calculations is provided in the appendix.

\section{Material cost}

As presented by Ruffo et al. [34] for the case of laser sintering, direct cost in AM are affected by the material cost, the part volume and wasted material. This also applies to the DLP technology, where the final material usage is composed of the part itself, support structures and excess resin covering the build's surface before washing. Usage of two-component resins leads to additional waste because of fast solidification, which prevents it from being re-used in a second print cycle. Translated into a CER, the material cost per part $C_{M a t}$ can be expressed as follows.

$C_{M a t}=\frac{\left(V_{B}+V_{S}+V_{E}\right) \cdot c_{M a t}}{N_{P, B}}$

$V_{B}$ describes the part build volume, $V_{S}$ the amount of support volume per build and $V_{E}$ comprises unsolidified excess material lost through adhesion and beginning age hardening. These volumes are multiplied with the specific resin cost $c_{\text {Mat }}$ divided by the number of parts fabricated in a single build $N_{P, B}$. The amount of waste material is measured through weighing in the print experiment.

\section{Manufacturing cost}

As part of the manufacturing cost, labor cost per part $C_{L}$ are affected by manual processing activities multiplied with the labor rate $c_{L}$. The time for resin dispensing $t_{D}$, the cumulative time for loading and unloading of the printer, part washer and posttreatment oven as handling time $t_{H}$ as well as the time for manual equipment cleaning $t_{C}$ can be assigned to the number of parts per build $N_{P, B}$. De-supporting takes the time $t_{D S}$ and is accounted for each part individually. Equipment cleaning after a shift is represented through $t_{S C}$ and distributed over the number of parts manufactured during a shift $N_{P, S}$.

$C_{L}=\left(\frac{b \cdot\left(t_{D}+t_{H}\right)+t_{C}}{N_{P, B}}+t_{D S}+\frac{t_{S C}}{N_{P, S}}\right) \cdot c_{L}$

As the model investigates the effects of automation on the part production cost, the parameters $t_{D}$ and $t_{H}$ are set to zero when the model is run.

$b= \begin{cases}1, & \text { for manual processes } \\ 0, & \text { for automated processes }\end{cases}$

This assumes automation of dispensing and loading activities through continuous dispensing and robot utilization for handling 


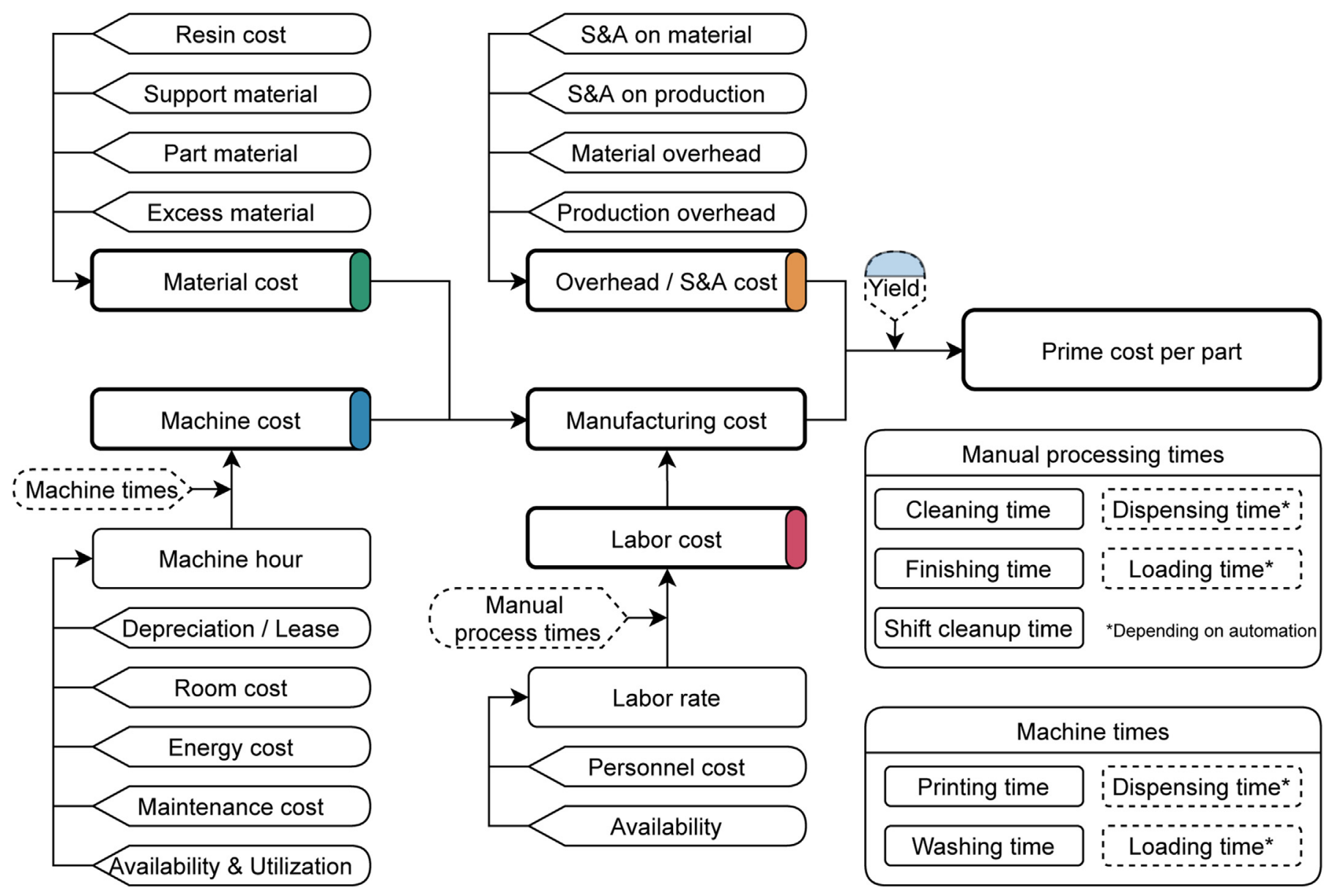

Fig. 7. Flowchart illustrating the components and parameters of the activity-based DLP cost model.

operations. These activities are then accounted for with machine times.

For allocation of the machine cost to the manufacturing cost, the cost per machine hour for the different used equipment needs to be calculated. This follows a common pattern for each equipment besides the curing oven.

$c_{M a c, i}=c_{E, i}+\frac{c_{R, i}+c_{D L, i}}{t_{A, i} \cdot k_{U, i}}$

Machine hours of the respective equipment (indexed with i) $c_{M a c, i}$ are characterized through the hourly equipment energy cost $c_{E, i}$, room cost $c_{R, i}$ and depreciation respectively lease cost $c_{D L, i}$. These figures are divided by the time of machine availability $t_{A, i}$ and utilization rate $k_{U, i}$. The different machine $\operatorname{cost} C_{M a c, i}$ are then calculated by multiplying the respective equipment's machine hour rate $c_{M a c, i}$ with the associated processing times $t_{i}$ (e.g., printing time $t_{P}$, washing time $t_{W}$ ) and can be broken down to single parts via the number of parts on a build platform $N_{P, B}$.

$C_{M a c, i}=\frac{c_{M a c, i} \cdot t_{i}}{N_{P, B}}$

Cost for the curing oven are attributed to a day's part output $N_{P, D}$, as it is assumed that oven capacity is selected according to the installed printing volume and curing time takes over $12 \mathrm{~h}$. The cost for automation equipment and the simulated production environment of the L1 printer, which is not available at the facility, have been estimated based on publicly available data and expert guesses or extrapolation of the equipment cost in the production environment of the M1 and M2 printer.

Overhead, yield and SE'A cost

Overhead and sales and administration cost are estimated by applying standard overhead rates to the production cost. The selected values shown in Table 3 reflect experts' assumptions for a small to medium-sized polymer processing facility. The yield assumption is derived from operation experience with optimized DLP builds.

\section{Sensitivity analysis}

To investigate the influence of selected cost drivers on the proposed cost model's output, a sensitivity analysis is conducted. The selected parameters of the cost model are varied in their input to detect their effect on the model output and reveal potentials for further cost savings when using DLP in a rapid manufacturing

Table 3

Rates applied for overhead, S\&A cost and yield.

\begin{tabular}{ll}
\hline Parameter & Rate in \% \\
\hline Material overhead & 4 \\
Production overhead & 15 \\
S\&A on material & 5 \\
S\&A on production & 5 \\
Yield & 95 \\
\hline
\end{tabular}


environment. The selection of parameters of interest can be oriented on the following three aspects:

- Significant contribution of the parameter to the prime cost.

- Technical parameters, which are influenceable by user and operation concept.

- Parameters, which are likely to be negotiable at resource purchase.

As frequently not all technical parameters are freely accessible on AM machines, the selection depends on the utilized equipment. For example, machines can limit the variation of print speed in the user interface for machine protection or quality reasons. Also, for the course of this work, parameters associated with the part orientation or geometry are excluded but have an influence on prime cost. However, this case study assumes a qualified build job and explores the cost drivers based on a fixed geometrical layout. Identified parameters and their effects will be presented after analysis of the prime cost structure.

\section{Application to a case study}

\section{Print setup for the case study}

The following paragraphs describe the evaluation of a case study using the proposed assessment framework. After selection of the print properties for different machines sizes, the print is executed on two printers. Results from this experimental print help to improve the accuracy of the cost modeling and sensitivity analysis. The obtained results are discussed after the presentation of the print setup.

\section{Part and print properties}

The case study is centered on an automotive exterior trim part with a low production volume. Properties and shape of the part are described in Table 4. For this print, the material of choice is Carbon's EPX 82 [41], which has been used in multiple automotive interior and exterior applications [12-14].

As the part features critical surfaces on side (b) which are exposed to the customer's view, the part needs to be printed at an angle to maintain a single-sided support attached solely to side (a). The process chain of printing and post-processing depends on the

Table 4

Shape and properties of the case study exterior part.

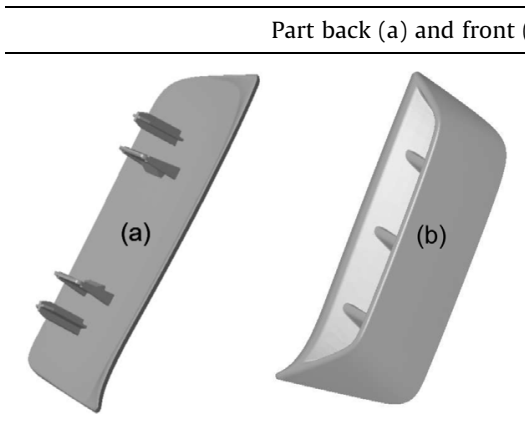

Bounding box X (supported) Bounding box Y (supported)

Bounding box $\mathrm{Z}$ (supported)

Part volume

Support volume

$[\mathrm{mm}]$

$[\mathrm{mm}]$

$[\mathrm{mm}]$

$\left[\mathrm{cm}^{3}\right]$

$\left[\mathrm{cm}^{3}\right]$ selected base material. For EPX 82, Table 5 summarizes the resulting processing steps, duration and necessary equipment.

After the print duration $\left(t_{p}\right)$ of $304 \mathrm{~min}$, the build platform is washed in the part washer and dunked in IPA $\left(t_{W}\right)$ for $16 \mathrm{~min}$. After support removal, the green part is thermally cured in an industrial oven for $750 \mathrm{~min}\left(t_{T C}\right)$.

\section{Nesting results}

Support generation was done using the Carbon printer interface with its support generation feature and manual support adjustments to clear critical surfaces. The resulting supported single-part STL file was used to nest the same supported part on all considered printer platforms. Because of the isotropic build quality of DLP systems, the nesting of parts was optimized towards the highest platform utilization without maintaining a standardized orientation. This contributes to economical print optimization and lower cost per part.

Referring to the different printers' specifications, the print jobs were nested using Materialise MAGICS. Table 6 summarizes the nesting results for the physically present M1 and M2 printers and the estimation for the L1 platform based on publicly available data. The realized part number per print varies between 2 parts for the small M1 platform and 24 parts for the L1 platform.

\section{Cost model parameter gathering}

For check of printability and gathering parameters like process step timings and resin loss, the print jobs have been executed on a Carbon M1 and M2 printer using EPX 82 resin. Tracked times for processing steps influenced the parameter selection in the cost model and sensitivity analysis. Fig. 8 shows the parts on the M2's build platform after the finished print. During the prints on the M1 and M2 platforms, the print duration and resin loss due to adhesion to part and printer surfaces as well as residual resin were recorded. Table 7 summarizes these parameters.

The residual resin volume sticking to the part's unwashed surface was weighed out at $2.5 \mathrm{ml}$ per part. Residual resin left in the printers after job finishing was measured at $62.4 \mathrm{ml}$ for the $\mathrm{M} 1$ and $116.7 \mathrm{ml}$ for the $\mathrm{M} 2$, resulting in $67.3 \mathrm{ml}$ of excess resin for the M1 and $131.5 \mathrm{ml}$ for the M2 printer. As build platform size doubles between M1 and M2, the excess resin amount (part surface and printer residuals) grows with nearly the same rate, namely with a factor of 1.95. Broken down to the printer's surface, this equals a resin loss of $0.60 \mathrm{ml} / \mathrm{cm}^{2}$ for the $\mathrm{M} 1$ and $0.58 \mathrm{ml} / \mathrm{cm}^{2}$ for the $\mathrm{M} 2$. This is used to estimate specific resin loss on the L1 platform at around $0.55 \mathrm{ml} / \mathrm{cm}^{2}$.

The print duration of $5 \mathrm{~h}$ and $4 \mathrm{~min}$ on both $\mathrm{M} 1$ and $\mathrm{M} 2$ result in an effective print speed of $23.3 \mathrm{~mm} / \mathrm{h}$. This equals a build rate of $13.8 \mathrm{~cm}^{3} / \mathrm{h}$ (M1) and $41.3 \mathrm{~cm}^{3} / \mathrm{h}(\mathrm{M} 2)$. Based on the achieved print speed and larger platform size, the build rate of the L1 platform is estimated at $162.2 \mathrm{~cm}^{3} / \mathrm{h}$.

As predicted by the printer interface, the builds came out without noticeable errors or surface irregularities. Generated support could be easily separated from the part bodies. Upon successful completion of the build job, the parameters for this print setup were handed to the model parameter lists.

Table 5

Processing steps and necessary equipment for parts produced with EPX 82.

\begin{tabular}{lll}
\hline Step & Duration $[\mathrm{min}]$ & Equipment \\
\hline Print & 304 & Printer \\
Washing & 16 & Washer \&IPA bath \\
Support removal & 2 & - \\
Thermal curing & 750 & Oven \\
\hline
\end{tabular}


Table 6

Nesting results of the case study part on the Carbon M1, M2 and L1 printer platform.

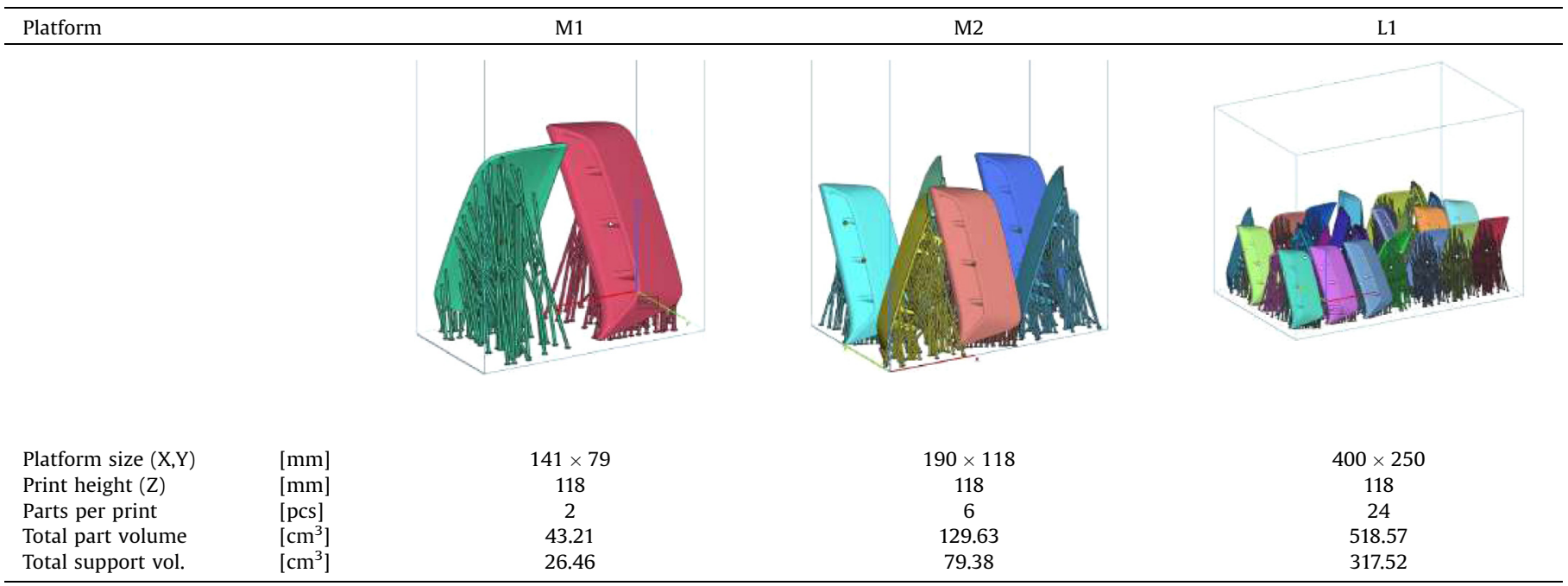

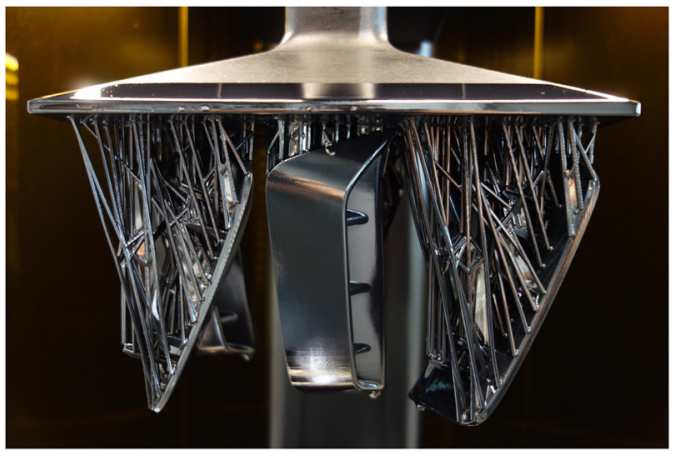

Fig. 8. Case study parts after successfully finished printing experiment on the Carbon M2 platform.

Table 7

Parameters recorded during the experimental prints and resulting estimations for the $\mathrm{L} 1$ platform.

\begin{tabular}{llccc}
\hline & & M1 & M2 & L1* \\
\hline Adhesive loss per part & {$[\mathrm{ml}]$} & 2.5 & 2.5 & 2.5 \\
Excess resin loss per print & {$[\mathrm{ml}]$} & 62.4 & 116.7 & 490.7 \\
Specific resin loss & {$\left[\mathrm{ml} / \mathrm{cm}^{2}\right]$} & 0.60 & 0.58 & 0.55 \\
Print speed & {$[\mathrm{mm} / \mathrm{h}]$} & 23.3 & 23.3 & 23.3 \\
Build rate & {$\left[\mathrm{cm}^{3} / \mathrm{h}\right]$} & 13.8 & 41.3 & 162.2 \\
\hline
\end{tabular}

\section{Calculated prime cost per part}

Upon execution of the cost model, the prime cost per part for a production environment surrounding the different printer platforms are calculated. Fig. 9 summarizes the results, listing the expected total production cost per part and their composition on the respective platform. Cost shares displayed on the inner ring are cumulative values attributed to the categories of material, labor, machine, overhead and expected yield cost. To get an impression about the dimensions of important cost contributing to each of these categories, the outer ring displays selected cost components calculated by the model. The detailed view provides support for pre-selection of cost drivers for analysis in the subsequent sensitivity analysis. Components of yield and overhead costs are not displayed because these have been applied to the model as fixed rates which are not containing further information.

The prime cost per part show strong dependence on platform size, reaching from $48.51 €$ for the smallest M1 platform to $17.87 €$ on the L1 platform. However, the cost decrease is not proportional to platform size increase, as the L1 platform realizes a reduction of about $13.2 \%$ over the five-times smaller M2 platform while doubling the platform size between the M1 and M2 platforms reduces part cost by $57.6 \%$. While the share of machine cost for the M1 and M2 is nearly equal between $42.6 \%$ and $40.7 \%$, it rises to $52.8 \%$ with usage of the L1 platform. Especially for the large build platform, the printer contributes the major share of machine cost, which represents the highest cost component. Other researchers reported comparable findings regarding the high impact of machine cost on part cost in multiple AM processes $[33,34,36]$. These point towards a high relevance of the printing speed and machine investment, respectively, lease cost as a cost driver. Lindemann et al. [42] also reported on the effect of these parameters.

Material cost comprise the material consumed for the part body, supports and the excess resin which is washed off the parts or left in the printer after a completed build job. Because of the printing duration of over $5 \mathrm{~h}$, excess resin cannot be reused. Its two-component formulation leads to an ongoing solidification process and degradation of printing properties, so excess material needs to be disposed. Across all platforms this effect causes the highest share in material cost ranging between $3.4 \%$ and $6.4 \%$ of part cost. As support material also needs to be disposed, these parameters also represent a high cost-driving and optimization potential. In general, the share of material cost increases with the build platform size from $7.0 \%$ to $16.2 \%$.

Labor cost develop inversely proportional to platform size and part number per print, ranging from $30.2 \%$ to $11.5 \%$. Using bigger platforms, cost for manual activities like cleaning and machine preparation are distributed over a higher number of parts per print, leading to a decrease of labor cost from $30.2 \%$ to $11.5 \%$ with increasing platform size. However, the amount of finishing cost increases from $1.9 \%$ to $5.0 \%$ because a growing number of parts needs individual support removal and handling. As all manual activities are assumed to be efficiently organized, the labor rate 
M1

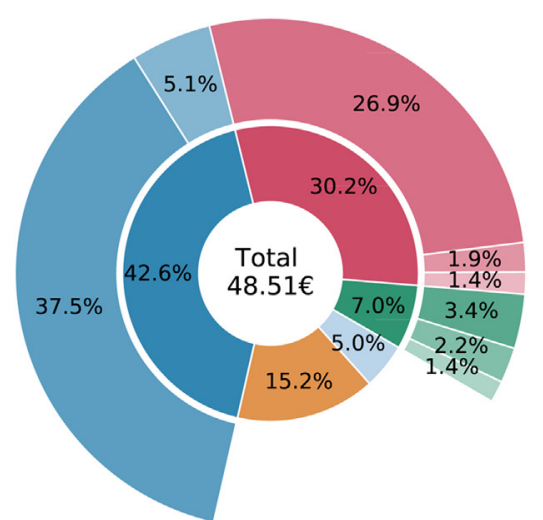

M2

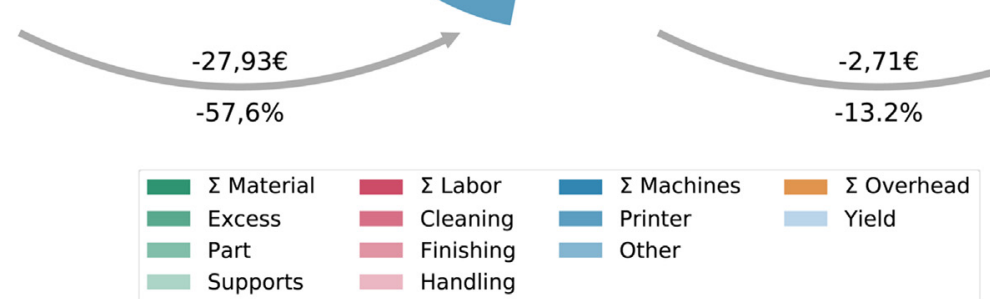

L1

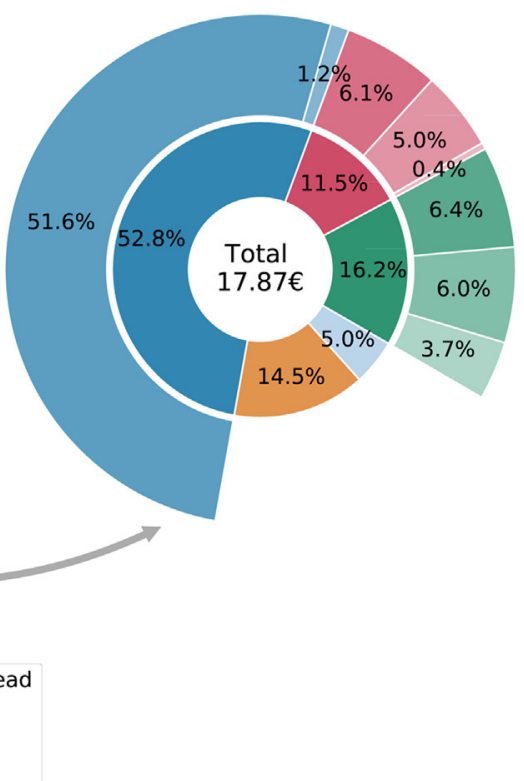

Fig. 9. Overview of the calculated prime cost per part and their components for the M1, M2 and L1 printer platform.

and underlying personnel cost are identified as a potential cost driver. Regarding the growing number of concepts for automation between printers as mentioned in "Introduction" section, the cost saving potential for automation of handling operations seems to be limited as these activities contribute to less than $1.4 \%$ of prime cost for all platform sizes. The following section presents the effects of a partially automated production environment on the prime cost per part.

\section{Effects of platform handling automation}

Recently proposed automation approaches use a robot arm or conveyor system to automatically load and unload finished prints from printers and post-processing equipment. As shown in Fig. 9 for a manual production approach, the cost for manual handling activities represent a minor cost component when it comes to total labor cost. The cost model is executed again, modeling automated handling and resin dispensing. Additional automation equipment is contributed for in the machine hour rate. Table 8 summarizes the effects of handling automation for the different platform sizes.

The results underline the limited effect of handling automation in production setting for this case study, realizing cost reductions between $0.5 \%$ and $1.2 \%$. As the contribution of handling cost to the total labor cost per part decreases with increasing platform size, handling automation becomes less attractive for these machines. Regarding the subsequent sensitivity analysis, parameters for handling automation are not considered impactful cost drivers.

\section{Cost driver evaluation}

The following paragraphs evaluate the role and effect of selected cost drivers on the part prime cost for the presented case study using the sensitivity analysis method as introduced in "Sensitivity analysis" section. Based on the presented reasoning pattern, six parameters are identified for sensitivity analysis. Printer lease cost and print speed mainly determinate the printer machine cost. Changes in these parameters due to alteration of
Table 8

Change in cost per part through handling automation.

\begin{tabular}{lllll}
\hline & & M1 & M2 & L1 \\
\hline Machine cost & {$[€]$} & +0.25 & +0.08 & +0.02 \\
Labor cost & {$[\%]$} & +1.2 & +1.0 & +0.2 \\
\multirow{3}{*}{ Overhead \&yield cost } & {$[€]$} & -0.68 & -0.23 & -0.08 \\
& {$[\%]$} & -4.6 & -4.2 & -3.6 \\
& {$[€]$} & -0.11 & -0.03 & -0.01 \\
Cost per part & {$[\%]$} & -1.1 & -0.9 & -0.4 \\
& {$[€]$} & -0.54 & -0.18 & -0.07 \\
& {$[\%]$} & -1.2 & -1.0 & -0.5 \\
\hline
\end{tabular}

print speed or lease price negotiations are expected to have a high impact on part cost. The same logic applies to the general resin price and material waste during production, comprising support and excess resin. These factors are influenced through print optimization or varying material prices. As activities requiring labor are assumed to be efficiently organized, the underlying cost driving parameter is operator cost. These cost also vary depending on the location of production and therefore pose an influenceable cost driver. A first category summarizes the negotiable, resourcerelated cost drivers such as cost for printer lease, operator and resin cost. Cost drivers like print speed, the resin loss and support volume, which can be influenced by build optimization, are listed in a second category.

All parameters are varied within a range of $\pm 20 \%$ around their original value for comparison of their effect on the part cost. Their behaviour is depicted in Fig. 10 with the first cost driver category listed in the upper graph row and the second category in the row below. For every cost driver and printer platform, the listed slope of the linear (regression) function indicates the responsiveness of the cost model to the input parameter variation. It can be interpreted as change in part cost per percent of change in the input parameters. 

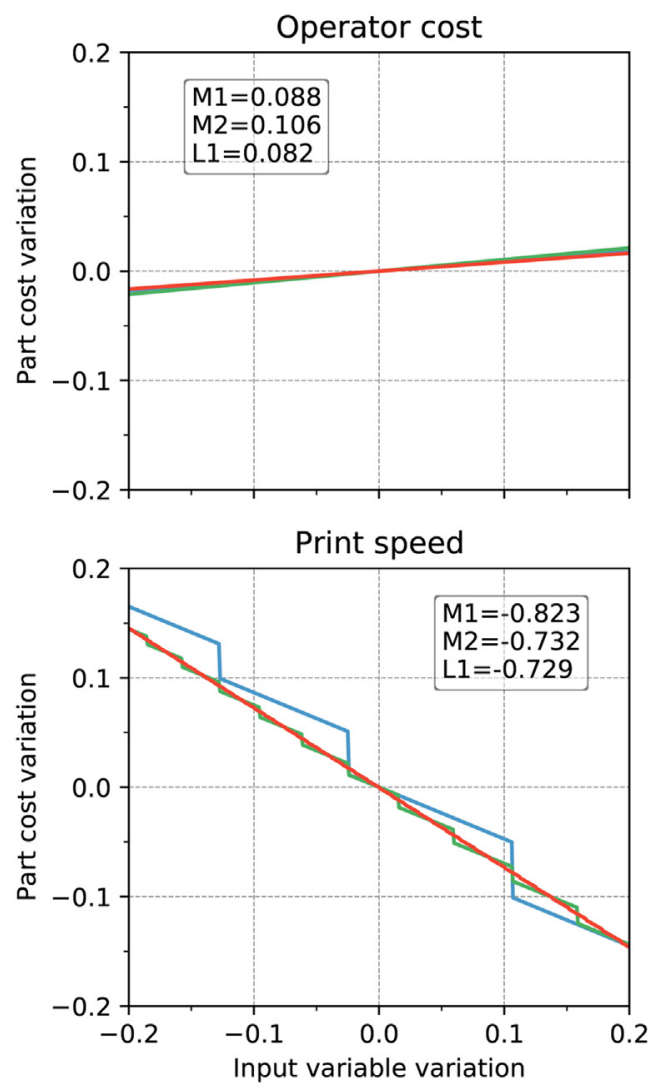
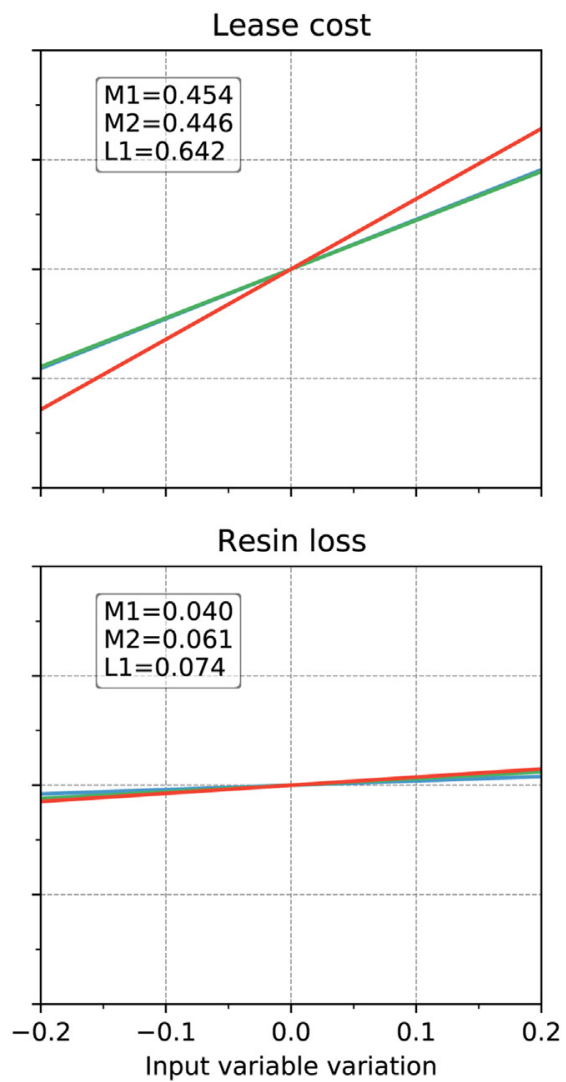
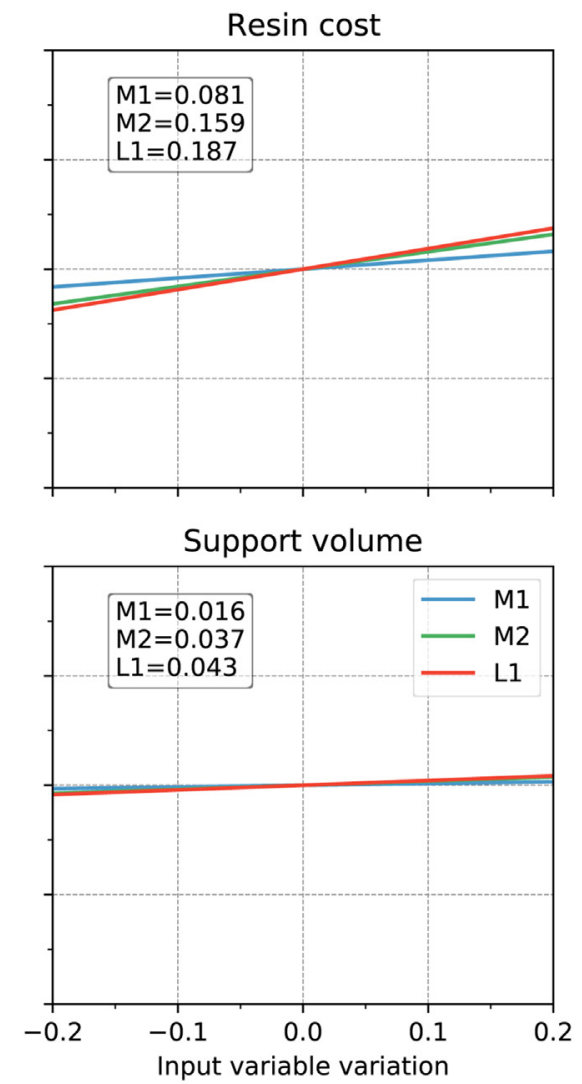

Fig. 10. Overview of the cost driver sensitivity for the selected parameters on M1, M2 and L1 printer platform.

For parameters associated with the first category, printer lease cost represent the most impactful cost driver. Ranging between a responsiveness of 0.454 for the small M1 platform to 0.642 for the L1 platform. Compared to operator cost and resin cost, here the spread between the different platforms is also the highest. While the responsiveness to changes in operator cost is very low for each platform, ranging from 0.082 (L1) to 0.106 (M2) with a small spread, a more clear dependence on resin cost is present. Here, increase in resin cost influences the large L1 platform the most, having a responsiveness of 0.187 .

With regard to the second category of cost drivers, which are influenceable through technical adjustments and optimizations, changes in print speed by far have the highest effect on part cost. Furthermore, due to the modeled shift system and the use of a floor function inside calculations for the realized parts per day $N_{P, D}$ (see Table 11 in the Appendix), the behavior is non-linear. Taking into account the linear regression slope coefficients, the small M1 platform has the highest responsiveness $(-0.823)$ to changes in print speed. With a mediocre spread, the L1 platform shows the lowest responsiveness with a value of -0.729 . For the other two cost drivers, resin loss and support volume, spread and responsiveness are very low. For resin loss, values between 0.040 (M1) and 0.074 (L1) are reported. Even lower values apply to support volume, ranging between a responsiveness of 0.016 (M1) and 0.043 (L1).

Expressed as changes in absolute part cost for a more practical perspective, Table 9 exemplarily summarizes the absolute variation results of the most impactful cost drivers 'Lease cost', 'Resin cost' and 'Print speed' for the different print platforms.

In general, these figures underline the potential impact of cost driver optimization, especially given the automotive background of the application example. Regardless of a make or buy approach, the
Table 9

Absolute change in part cost at variation boundaries $( \pm 20 \%)$.

\begin{tabular}{llllll}
\hline & Variation & M1 & M2 & L1 & Unit \\
\hline Lease cost & $\pm 20 \%$ & \pm 4.41 & \pm 1.84 & \pm 2.29 & {$[€]$} \\
Resin cost & $\pm 20 \%$ & \pm 0.79 & \pm 0.65 & \pm 0.67 & {$[€]$} \\
Print speed & $+20 \%$ & -8.01 & -2.98 & -2.59 & {$[€]$} \\
& $-20 \%$ & +7.03 & +2.95 & +2.61 & {$[€]$} \\
\hline
\end{tabular}

cost sensitivity for sourcing of automotive parts is very high and thus demands economic optimization. Also, careful weighing of chances and risks related to cost drivers is mandatory.

\section{Discussion}

\section{Conclusions}

The developed cost assessment framework and its application to the case study generated valuable insights into the cost structure of series production with DLP. It enables an assessment of cost structures for physically present printers and production systems as well as estimation for machines that might be subject to an investment or available at suppliers. Fundamental findings from the case study showed that increasing printer size positively influences prime cost per part. However, the relation is not proportional because of varying shares of machine cost. As already found in investigations of other AM processes, machine cost also contributes the highest share in part prime cost with DLP, ranging from about $37 \%$ to $52 \%$. Consequently, cost drivers associated with machine cost like machine lease price or print speed bring the highest potential for further production cost reductions as detected in the sensitivity analysis. 
With increasing platform size, the contribution of labor cost decreases, as time-intensive activities like machine cleaning between build jobs are distributed over a higher number of parts per print. However, the same applies to the cost of handling part platforms between prints and post processing. Thus, the effect of automation of handling activities on the part cost is very limited and decreases with increasing platform size. This applies to this case study, but could significantly change when another production model and shift-system is assumed. In contrast to handling, cost attributed to single part finishing activities become more relevant with a higher number of parts produced in a print. This underlines the need for new automation concepts for support removal and part finishing to lower prime cost in production.

The importance of material cost also grows with the platform size. Though bigger platforms operate more efficient concerning unused resin, high cost shares and thus also high potentials for cost optimization lie in the reduction of support structures and excess resin. In this case study, the degradation of two-component resins during longer print times leads to a high amount of unused resin which is not usable for a subsequent print and thus needs to be disposed. Here, development and application of single-component resins with comparable properties can improve the process cost and sustainability.

In general, bigger print platforms correlate with reductions in part cost in the analyzed case study. For all platform sizes the optimization of build-related cost drivers like print speed, material waste and support volume shows a high potential for further cost reductions. These parameters can often be influenced by the user depending on the build preparation and execution.

\section{Limitations and future research}

The proposed framework enables first estimations of part cost on different DLP platforms in a rapid manufacturing context. Though some build and model parameters were gathered through a sample print, other parameters are subject to the user's assumptions. It is questionable if the assumed parameters can realistically be achieved in the final production environment. However, for the targeted early product development phase, the approach offers a detailed breakdown of cost and influence of cost drivers, enabling first profound decision making regarding, e.g., utilized printer platforms and the operation concept or checking the plausibility of supplier quotes. Furthermore, its elements can be carried forward to a dynamic cost evaluation in a simulation environment, further enhancing cost estimations together with production times and necessary equipment.

The case study showed that the part cost difference between the two larger platforms is relatively low. Depending on the production volume, it might also be beneficial to produce on smaller machines, as they can face higher utilization in practice. Especially when larger machines are not fully utilized, the high investment, respectively, lease cost can lead to significant increases in part cost, underlining the need for an applicationspecific dynamic cost modeling approach.

While DLP already proves its capability to fulfill end-use parts' requirements and moves into series production like other AM technologies, there are still opportunities for further cost reductions in both, production resources and build optimization for DLP. For example, effects from alternative part positioning, supporting or redesign for additive manufacturing were not considered but are directly linked to the cost during production. Furthermore, improved support generation and minimization of waste not only contribute to better cost performance but also to a more sustainable manufacturing process with DLP. In this context, additional benefits of AM such as the possibility to produce locally in distributed manufacturing networks were not covered here but need to be considered when AM is evaluated among other manufacturing options. Multiple effects down the supply chain should be taken into account to estimate the cost of AM and its sustainability in production in a more holistic way. Future research can address these topics and contribute to more cost transparency in this AM process family, ultimately advancing usage of AM in manufacturing through better cost prediction in the early product development stages.

\section{Conflicts of interest}

None declared.

\section{Appendix A. Additional information for parameters and calculations}

This appendix provides additional information about relevant parameters and calculations, which where applied during development of the cost model and its application to the presented case study.

\section{A.1 Parameter notation and overview}

Multiple parameters have been identified and acquired for the proposed cost model. For better understanding and transparency, these parameters are listed in Table 10 with their respective notation, grouped by their type.

Table 10

Summary of parameters for model input.

\begin{tabular}{|c|c|c|}
\hline Parameter & Symbol & Unit \\
\hline Printer platform $\mathrm{x}$ size & $x$ & {$[\mathrm{~mm}]$} \\
\hline Printer platform y size & $y$ & {$[\mathrm{~mm}]$} \\
\hline Geometric part volume & $V_{G, P}$ & {$\left[\mathrm{~cm}^{3}\right]$} \\
\hline Geometric support volume & $V_{G, S}$ & {$\left[\mathrm{~cm}^{3}\right]$} \\
\hline Part bounding box $\mathrm{x}$ size & $x_{B, P}$ & {$[\mathrm{~mm}]$} \\
\hline Part bounding box y size & $y_{B, P}$ & {$[\mathrm{~mm}]$} \\
\hline Part bounding box z size & $z_{B, P}$ & {$[\mathrm{~mm}]$} \\
\hline Printer room footprint & $A_{F, P}$ & {$\left[\mathrm{~m}^{2}\right]$} \\
\hline Washer room footprint & $A_{F, W}$ & {$\left[\mathrm{~m}^{2}\right]$} \\
\hline Oven room footprint & $A_{F, O}$ & {$\left[\mathrm{~m}^{2}\right]$} \\
\hline Printer power rating & $P_{E, P}$ & {$[\mathrm{~kW}]$} \\
\hline Washer power rating & $P_{E, W}$ & {$[\mathrm{~kW}]$} \\
\hline Robot power rating & $P_{E, R}$ & {$[\mathrm{~kW}]$} \\
\hline Oven power rating & $P_{E, O}$ & {$[\mathrm{~kW}]$} \\
\hline Number of parts per build & $N_{P, B}$ & - \\
\hline Number of shifts per day & $n_{S}$ & - \\
\hline Number of operational days per year & $n_{0}$ & - \\
\hline Lease for printer and platforms & $C_{D L, P}$ & {$[\mathrm{k} € / \mathrm{a}]$} \\
\hline Lease for part washer & $c_{D L, W}$ & {$[\mathrm{k} € / \mathrm{a}]$} \\
\hline Invest cost for robot and periphery & $C_{I, R}$ & {$[\mathrm{k} € / \mathrm{a}]$} \\
\hline Invest cost for curing oven & $C_{I, 0}$ & {$[\mathrm{k} € / \mathrm{a}]$} \\
\hline Resin cost & $c_{\text {Mat }}$ & {$[€ / \mathrm{L}]$} \\
\hline Operator cost & $c_{L}$ & {$[€ / \mathrm{h}]$} \\
\hline Printing time & $t_{P}$ & {$[\mathrm{~h}]$} \\
\hline Washing time & $t_{W}$ & [min] \\
\hline Resin dispensing & $t_{D}$ & {$[\mathrm{~min}]$} \\
\hline Platform handling & $t_{H}$ & [min] \\
\hline Platform cleaning & $t_{C}$ & {$[\mathrm{~min}]$} \\
\hline Part de-supporting & $t_{D S}$ & {$[\mathrm{~min}]$} \\
\hline Thermal curing & $t_{T C}$ & {$[\mathrm{~h}]$} \\
\hline Shift clean-up time & $t_{S C}$ & [h] \\
\hline Time per shift & $t_{S}$ & [h] \\
\hline Depreciation time & $t_{D e p}$ & [a] \\
\hline Specific resin loss & $k_{L}$ & {$\left[\mathrm{ml} / \mathrm{cm}^{2}\right]$} \\
\hline Printer utilization & & - \\
\hline
\end{tabular}


Table 10 (Continued)

\begin{tabular}{lll}
\hline Parameter & Symbol & Unit \\
\hline & $k_{U, P}$ & - \\
Washer utilization & $k_{U, W}$ & - \\
Robot utilization & $k_{U, R}$ & - \\
Oven utilization & $k_{U, O}$ & - \\
Maintenance factor & $k_{M}$ & - \\
S\&A on material & $k_{S A, M}$ & - \\
S\&A on production & $k_{S A, P}$ & - \\
Overhead on material & $k_{O, M}$ & - \\
Overhead on production & $k_{O, P}$ & - \\
Yield & $k_{Y}$ & {$[€ / \mathrm{kWh}$} \\
Power rate & $k_{E}$ & {$\left[€ / \mathrm{m}^{2} \mathrm{a}\right]$} \\
Room rate & $k_{R}$ & - \\
Conversion rate $\$ / €$ & $k_{C}$ & \\
\hline
\end{tabular}

Table 11

Summary of calculated parameters and cost estimating relationships.

\begin{tabular}{|c|c|c|}
\hline Parameter & Equation & Unit \\
\hline Part volume per build & $V_{B}=N_{P, B} \cdot V_{G, P}$ & {$\left[\mathrm{~cm}^{3}\right]$} \\
\hline Support volume per build & $V_{S}=N_{P, B} \cdot V_{G, S}$ & {$\left[\mathrm{~cm}^{3}\right]$} \\
\hline Excess volume per build & $V_{E}=k_{L} \cdot x \cdot y$ & {$\left[\mathrm{~cm}^{3}\right]$} \\
\hline Print speed & $v_{P}=\frac{z_{B, P}}{t_{P}}$ & {$[\mathrm{~cm} / \mathrm{h}]$} \\
\hline Average build rate & $b_{P}=\frac{V_{B}+V_{S}}{t_{P}}$ & {$\left[\mathrm{~cm}^{3} / \mathrm{h}\right]$} \\
\hline Material cost per part & $C_{\text {Mat }}=\frac{\left(V_{B}+V_{S}+V_{E}\right) \cdot c_{M a t}}{N_{P B}}$ & {$[€]$} \\
\hline Labor cost per part & $C_{L}=\left(\frac{t_{D}+t_{H}+t_{C}}{N_{P, B}}+t_{D S}+\frac{t_{S C}}{N_{P S}}\right) \cdot c_{L}$ & {$[€]$} \\
\hline Machine hour & $c_{M a c, i}=c_{E, i}+\frac{c_{R, i}+c_{D L, i}}{t_{A, i} \cdot k_{L, i}}$ & {$[€ / \mathrm{h}]$} \\
\hline Equipment energy cost & $c_{E, i}=P_{E, i} \cdot k_{E}$ & {$[€ / \mathrm{h}]$} \\
\hline Equipment room cost & $c_{R, i}=A_{F, i} \cdot k_{R}$ & {$[€ / \mathrm{a}]$} \\
\hline Daily availability & $t_{A, D, i}=n_{S} \cdot\left(t_{S}-t_{S C}\right)$ & {$[\mathrm{h}]$} \\
\hline Yearly availability & $t_{A, i}=n_{O} \cdot t_{A, D, i}$ & {$[\mathrm{~h} / \mathrm{a}]$} \\
\hline Printer machine cost & $C_{M a c, P}=\frac{c_{M a c, p} \cdot t_{P}}{N_{P, B}}$ & {$[€]$} \\
\hline Washer machine cost & $C_{M a c, W}=\frac{c_{M a c, W} \cdot t_{W}}{N_{P, B}}$ & {$[€]$} \\
\hline Robot machine cost & $C_{M a c, R}=\frac{c_{M a c, R} \cdot t_{H}}{N_{P, B}}$ & {$[€]$} \\
\hline Oven machine cost & $C_{M a c, O}=\frac{c_{M a c, 0} \cdot t_{T C}}{N_{P, D}}$ & {$[€]$} \\
\hline Robot depreciation cost & $c_{D L, R}=\frac{c_{I, R} \cdot k_{M}}{t_{D e p}}$ & {$[€ / a]$} \\
\hline Oven depreciation cost & $c_{D L, O}=\frac{C_{l, o} \cdot k_{M}}{t_{D e p}}$ & {$[€ / \mathrm{a}]$} \\
\hline Production cost & $C_{P}=C_{M a c, P}+C_{M a c, W}+C_{M a c, R}+C_{M a c, O}$ & {$[€]$} \\
\hline Parts per day & $N_{P, D}=\left|\frac{t_{A, D, P}}{t_{P}+t_{H}} \cdot k_{U, P} \cdot N_{P, B}\right|$ & \\
\hline Parts per shift & $N_{P, S}=\frac{N_{P, D}}{n_{S}}$ & - \\
\hline Total part cost before yield & $\begin{aligned} C_{\text {Part }, B Y}= & \left(C_{P}+C_{L}\right) \cdot\left(1+k_{S A, P}+k_{O, P}\right) \\
& +C_{M a t} \cdot\left(1+k_{S A, M}+k_{O, M}\right)\end{aligned}$ & {$[€]$} \\
\hline Total part cost after yield & $C_{\text {Part }, A Y}=\frac{C_{\text {Part. }, B Y}}{k_{Y}}$ & {$[€]$} \\
\hline
\end{tabular}

\section{A.2 Relationships for parameter calculation and cost-estimation}

The cost model introduced in "Cost model" section contains a number of cost estimating relationships and side calculations, which are necessary to conduct the sensitivity analysis and achieve the presented results. Table 11 provides an overview over all equations for the resulting cost-estimating relationships, which were applied in the model in addition to the relationships mentioned in the introduction of the cost model.

\section{References}

[1] Braess, H.-H., Seiffert, U., 2013, Vieweg Handbuch Kraftfahrzeugtechnik, ATZ/ MTZ-Fachbuch, 7., aktual. aufl. 2013 ed..Imprint: Springer Vieweg, Wiesbaden

[2] Reeves, P., Tuck, C., Hague, R., 2011, Additive manufacturing for mass customization. in Pham DD., Fogliatto FF.S.S, da Silveira GG.J.C.JC, (Eds.) Mass customization, volume 6 of Springer series in advanced manufacturing. Springer London, London, pp. pp.275-289.
[3] Maresch, D., Gartner, J., 2018, Make disruptive technological change happen the case of additive manufacturing. Technol Forecast Soc Change,

[4] Deloitte GmbH. 2019, Challenges of additive manufacturing. (last visited 14.06.21)https://www2.deloitte.com/content/dam/Deloitte/de/Documents/operations/ Deloitte_Challenges_of_Additive_Manufacturing.pdf.

[5] Wiese, M., Thiede, S., Herrmann, C., 2020, Rapid manufacturing of automotive polymer series parts: a systematic review of processes, materials and challenges. Addit Manuf, 36.

[6] Tofail, S.A., Koumoulos, E.P., Bandyopadhyay, A., Bose, S., O’Donoghue, L. Charitidis, C., 2018, Additive manufacturing: scientific and technological challenges, market uptake and opportunities. Mater Today, 21:22-37.

[7] Abdulhameed, O., Al-Ahmari, A., Ameen, W., Mian, S.H., 2019, Additive manufacturing: challenges, trends, and applications. Adv Mech Eng, 11:1-27.

[8] Gibson, I., Rosen, D.W., Stucker, B., 2010, Additive manufacturing technologies. Springer US, Boston, MA.

[9] Verein Deutscher Ingenieure. 2014, VDI 3405: Additive Fertigungsverfahren: Grundlagen, Begriffe, Verfahrensbeschreibungen.Beuth Verlag, Berlin.

[10] Galantucci, L.M., Guerra, M.G., Dassisti, M., Lavecchia, F., 2019, Additive manufacturing: new trends in the 4th industrial revolution. in Monostori LL., Majstorovic VV.D.D, Hu SS.J.J, Djurdjanovic DD., (Eds.) in: Proceedings of the 4 th international conference on the industry 4.0 model for advanced manufacturing, volume 13 of lecture notes in mechanical engineering. Springer International Publishing, Cham, pp. pp.153-169.

[11] DeSimone, J.M., Ermoshkin, A., Ermoshkin, N., Samulski, E.T., 2014, Continuous liquid interphase printing: WO2014126837A2.

[12] plasticsnews.com. 2019, BMW sees potential of 3D printing in new business models. (last visited 14.06.21)https://www.plasticsnews.com/news/bmw-sees-potential-3d-printing-new-business-models.

[13] 3dprintingindustry.com. 2018, Ford opens advanced manufacturing center and 3D prints Ford Shelby Mustang GT500 parts. (last visited 14.06.21)https:// 3dprintingindustry:com/news/ford-opens-advanced-manufacturingcenter-and-3d-printsford-shelby-mustang-gt500-parts-144889.

[14] 3dprintingindustry.com. 2019, Lamborghini Urus to feature 3D printed components made by Carbon. (last visited 14.06.21)https://3dprintingindustry:com/ news/lamborghini-urus-to-feature-3d-printed-components-made-bycarbon-148787.

[15] Carbon Inc. 2017, The perfect fit: Carbon + adidas collaborate to upend athletic footwear. (last visited 14.06.21)https://www.carbon3d.com/case-studies/adidas.

[16] 3D Printing Media Network. 2019, Adaptive: Carbon to 3D print high-performance bike saddle for fizik. (last visited 14.06.21)https://www:3dprintingmedia: network/carbon-3d-print-adaptive-bike-saddlefizik.

[17] Riddell Inc. 2019, Riddell partners with Carbon to produce first-ever 3D printed football helmet liner. (last visited 14.06.21)http://news.riddell.com/info/releases/ riddell-partners-with-carbonR-to-produce-first-ever-3d-printed-football-helmet-liner.

[18] 3D Printing Media Network. 2019, Carbon gets into the 3D printed eyewear game with Neuron4D sunglasses by JINS. (last visited 14.06.21)https:// www:3dprintingmedia:network/carbon-gets-into-the-3dprinted-eyewear-game-withneuron4d-sunglasses.

[19] 3dprintingindustry.com. 2020, Genera G2 DLP 3D printer and F2 post-processing unit - technical specifications. (last visited 14.06.21)https://3dprintingindustry:com/news/genera-g2-dlp-3d-printerand-f2-post-processing-unit-technical-specifcations-168022.

[20] Additive Manufacturing. 2020, Production 3D printing with roots in materials development: the origin story. (last visited 14.06.21)https://www.additivemanufacturing.media/blog/post/production-3d-printing-with-roots-in-materials-developmentthe-origin-story.

[21] adhesivesmag.com. 2019, HENKEL: open materials platform for additive manufacturing. (last visited 14.06.21)https://www.adhesivesmag.com/articles/ 96969-henkel-open-materials-platform-for-additive-manufacturing.

[22] Henkel AG. 2019, Henkel and origin to partner for additive manufacturing at scale. (last visited 14.06.21)https://www.henkel.com/press-and-media/press-releasesand-kits/2019-04-02-henkel-and-origin-to-partner-for-additive-manufacturing-at-scale906580.

[23] BASF SE. 2019, BASF 3D printing solutions and origin collaborate with footwear manufacturer ECCO. (last visited 14.06.21)https://www.basf.com/global/en/media/ news-releases/2019/05/p-19-214.html.

[24] Assembly Magazine. 2019, Additive manufacturing: the quest for automation: robots and other tools are key to mass-producing printed parts. (last visited 14.06.21)https://www.assemblymag.com/articles/95074-additive-manufacturing-thequest-for-automation.

[25] Curran, R., Raghunathan, S., Price, M., 2004, Review of aerospace engineering cost modelling: the genetic causal approach. Prog Aerosp Sci, 40:487-534.

[26] Niazi, A., Dai, J.S., Balabani, S., Seneviratne, L., 2006, Product cost estimation: technique classification and methodology review. J Manuf Sci Eng, 128:563575.

[27] Hueber, C., Horejsi, K., Schledjewski, R., 2016, Review of cost estimation: methods and models for aerospace composite manufacturing. Adv Manuf Polym Compos Sci, 2:1-13.

[28] Duverlie, P., Castelain, J.M., 1999, Cost estimation during design step: parametric method versus case based reasoning method. Int J Adv Manuf Technol, 15:895-906.

[29] Esawi, A., Ashby, M.F., 2003, Cost estimates to guide pre-selection of processes. Mater Des, 24:605-616.

[30] Ashby, M.F., 2004, Materials selection in mechanical design. 2nd ed. Butterworth-Heinemann, Amsterdam. (reprinted ed.).

[31] Spedding, T.A., Sun, G.Q., 1999, Application of discrete event simulation to the activity based costing of manufacturing systems. Int J Prod Econ, 58:289-301. 
[32] Costabile, G., Fera, M., Fruggiero, F., Lambiase, A., Pham, D., 2017, Cost models of additive manufacturing: a literature review. Int J Ind Eng Comput, 263-283.

[33] Hopkinson, N., Dickens, P., 2003, Analysis of rapid manufacturing-using layer manufacturing processes for production. Proc Inst Mech Eng Part C J Mech Eng Sci, 217:31-39.

[34] Ruffo, M., Tuck, C., Hague, R., 2006, Cost estimation for rapid manufacturing laser sintering production for low to medium volumes. Proc Inst Mech Eng Part B J Eng Manuf, 220:1417-1427.

[35] Charalambis, A., Davoudinejad, A., Tosello, G., Pedersen, D., 2017, Cost estimation of a specifically designed direct light processing (DLP) additive manufacturing machine for precision printing. Proceedings of the 17 th international conference of the European society for precision engineering and nanotechnology,

[36] Schröder, M., Falk, B., Schmitt, R., 2015, Evaluation of cost structures of additive manufacturing processes using a new business model. Proc CIRP, 30:311-316.
[37] Cunningham, C.R., Wikshåland, S., Xu, F., Kemakolam, N., Shokrani, A., Dhokia, V., Newman, S.T., 2017, Cost modelling and sensitivity analysis of wire and arc additive manufacturing. Proc Manuf, 11:650-657.

[38] Yang, Y., Li, L., 2018, Cost modeling and analysis for mask image projection stereolithography additive manufacturing: simultaneous production with mixed geometries. Int J Prod Econ, 206:146-158.

[39] Horsch, J., 2020, Kostenrechnung.Springer Fachmedien Wiesbaden, Wiesbaden

[40] Plinke, W., 1989, Industrielle Kostenrechnung für Ingenieure.Springer Berlin Heidelberg, Berlin, Heidelberg and s.l.

[41] Carbon Inc. 2018, EPX 82: Technical data sheet. (last visited 14.06.21)https://s3. amazonaws.com/carbon-static-assets/downloads/resin_data_sheets/EPX82_TDS.pdf.

[42] Lindemann, C., Jahnke, U., Habdank, M., Koch, R., 2012, Analyzing product lifecycle costs for a better understanding of cost drivers in additive manufacturing. 23rd Annual international solid freeform fabrication symposium - an additive manufacturing conference, . 